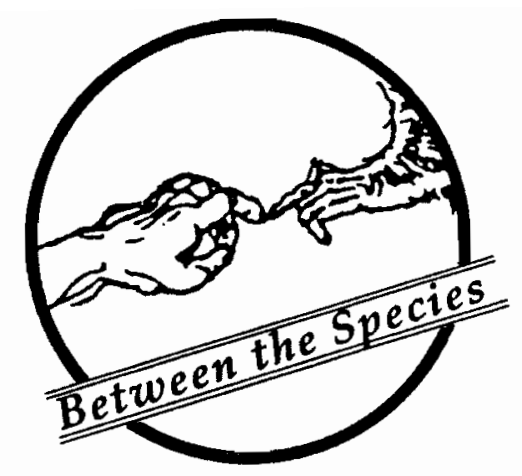

\title{
WHAT DOES RESPECT FOR NATURE MEAN?
}

\author{
Richard A. Watson \\ Washington University
}

A review of Paul W. Taylor's Respect

for Nature: A T heory of

Environmental Ethics (Princeton:

Princeton University Press, 1986).

329 pages, hardcover \$37.50, paperback \$12.50.

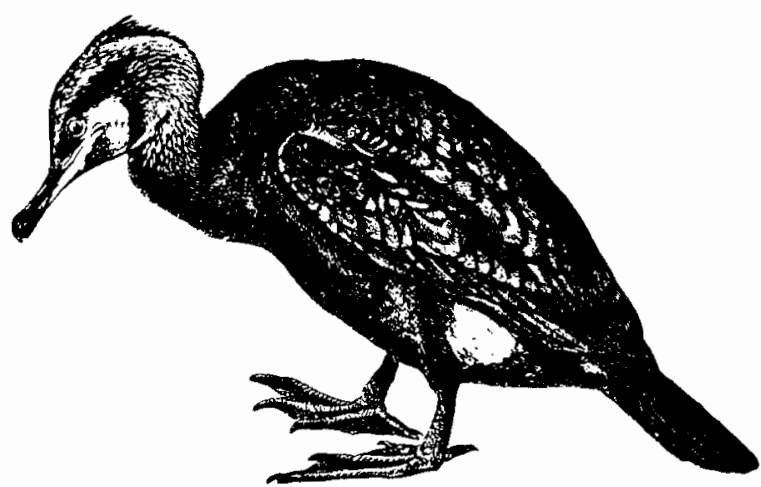

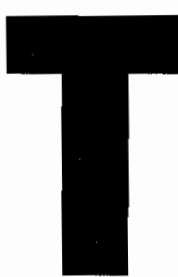

aylor develops a biocentric environmental ethics based on moral agents' respect for inherently worthy moral subjects in nature. Moral subjects consist of "rhe natural world ... the entire set of natural ecosystems on our planet, along with the populations of animals and plants that make up the biotic communities of those ecosystems" (3). Nature is thus the life-system consisting of all living organisms. 
Both human and environmental ethics incorporate the same notion of a moral agent as

any being that ... can act morally or immorally ... have duties and responsibilities ... be held accountable for what it does ... form judgments about right and wrong ... engage in moral deliberation ... consider and weigh moral reasons for and against various courses of conduct open to choice ... make decisions on the basis of those reasons ... exercise the necessary resolve and willpower to carry out those decisions ... hold [it] self answerable to others for failing to carry them out. (14)

Taylor's definition is in fact only of an agent. A moral agent not only must have the capacities of self-direction, but also must commit itself to a set of ultimate moral principles.

On Taylor's grounds, "not all humans are moral agents, and ... there may exist moral agents who are not human.... Perhaps dolphins, whales, elephants, and the primates possess ... sufficient understanding of their relationship to other members of their social group that they can see themselves as bearing responsibilities toward their fellows" (15). In sum, to be a moral agent an entity must be able to choose and act according to rules to which it has committed itself with self-conscious intention.

A moral subject is "any being that can be treated rightly or wrongly and toward whom moral agents can have duties and responsibilities [thus] it must be possible for such beings to have their conditions of existence be made better or worse by the actions of agents" (17). So "all moral agents are moral subjects" (16), but not "all moral subjects are moral agents" (17). To be a moral subject, an entity need not be a moral agent, but "it is always possible for a moral agent to take a moral subject's standpoint and make judgments from its standpoint about how it ought to be treated... [for] the furtherance or preservation of the well-being of the subject, not of the [moral agent] who does the judging" (17).

Crucially, being a moral subject depends on being an "entity-having-a-good-of-its-own" $(60)$, so that "it makes sense to speak of their being benefitted or harmed. Things that happen to them can be judged, from their standpoint, to be favorable or unfavorable to them" (63). The validity of Taylor's environmental ethics depends on whether or not an entity that lacks interests and self-consciousness - a subjective (self-conscious) sense of itself - can logically be said to have a standpoint from which its own good can be imaginatively projected by a moral agent.

Taylor says "it is possible for a human being [moral agent] to take [any] animal's standpoint and, without a trace of anthropomorphism, make a factually informed and objective judgment regarding what is desirable or undesirable from that standpoint" (67).

Taylor says every living organism has a-good-ofits-own and thus has inherent worth, which means that each is a moral subject that is worthy of respect by and has claims on moral agents (75). That an entity has a-good-of-its-own does not logically imply that it has inherent worth, but in taking the biocentric attitude a moral agent is committed to "the principle that living things ought not to be harmed or interfered with in nature, other things being equal" (72).

Inherent worth is distinguished from "intrinsic value," which pertains to "any activity ... carried on for its own sake or as an end in itself" (73), and from "inherent value," which pertains to anything "held in high esteem and considered important because it is the kind of thing it is" (73). Thus, a thing "has intrinsic value for those who find satisfaction in it" (73), and "the inherent value of anything is relative to and dependent upon someone's valuing it" (74). Living organisms may have intrinsic and/or inherent value depending on an agent's attitude toward them, but all have inherent worth, which is not "relativized to the subjective valuings of conscious beings" (74).

"Inherent worth ... is to be attributed only to entities that have a good of their own.... a living thing ... possesses such worth regardless of any instrumental or inherent value it may have with reference to the good of any other being" (75).

Taylor says that just as for human ethics "the idea that all persons are bearers of inherent worth just in virtue of their being persons ... is the ultimate ground of all duties in a moral community" (78), so also in environmental ethics all living organisms are bearers of inherent worth 
just in virtue of their being organisms. He claims that:

it is possible to establish the truth of the claim that a person has inherent worth by showing that only this way of regarding persons is coherent with the conception of every person as a rational, valuing being an autonomous center of conscious life. To see ourselves as such an entity and to assert our own inherent worth out of self-respect, while at the same time denying that worth to others whom we conceive to be persons like ourselves, is incoherent. (79)

Taylor uses this apparently tautological argument form to support his environmental ethics:

The same type of argument will also hold for the claim that all animals and plants in the natural world have inherent worth. We can establish the truth of that claim by showing that only this way of regarding them is coherent with how we must understand them when we accept the beliefsystem of the biocentric outlook on nature... The central tenet of the theory of environmental ethics that $\mathrm{I}$ am defending is that actions are right and character traits are morally good in virtue of their expressing or embodying a certain ultimate moral attitude, which I call respect for nature. (80)

Taylor says that the only way to argue for adopting an ultimate moral attitude is to exhibit what it would mean for moral agents to believe and act on it. Many such attitudes are possible:

[For example,] the exploitative attitude, no less than the attitude of respect, can be viewed as a supreme moral commitment that takes priority over all other norms and values, as far as the treatment of the natural world is concerned. The choice between these two ultimate, incompatible attitudes must then be based on whatever sound arguments can be given to show that adopting one and not the other as an ultimate moral attitude is justified on rational grounds. (96)
Ultimate moral principles cannot be deductively derived from first principles, but only holistically shown to be persuasive (14). Thus Taylor's "sound arguments" run in circles:

Now, in subscribing to or adopting that total structure of moral principles, we are taking a certain ultimate moral attitude and committing ourselves to expressing that attitude in our conduct and character. Our belief that the total system of principles constitutes a valid ethical system is identical with, and not a ground for, our belief that the ultimate moral attitude embodied in these principles is justified. Unlike the specific moral attitudes of approval and disapproval that we have toward human conduct and that follow from the ultimate attitude, the ultimate attitude itself does not follow from any more basic commitment...

In order to justify the attitude, then, we must show that the whole ethical system that embodies it is a valid one. How can this be done? The only way is to set forth the beliefsystem that underlies and supports the attitude and show that it is acceptable to all who are rational, factually informed, and have a developed capacity of realityawareness. (97-98)

The "capacity of reality-awareness" is the ability to take the standpoint of a non-self-conscious entity that is not a moral agent. (164-165)

Human ethics is based on the concept of a person that is wider than that of a moral agent:

A person ... is ... a center of autonomous choice and valuation. Persons are beings that give direction to their lives on the basis of their own values. They ... not only have interests and purposes, but also have the capacity to set long-range and short-range goals for themselves in the light of those interests and purposes. They have the power to decide for themselves what ends to seek in life and they can make up their own minds about the best means to take toward those ends. They have the ability to impose order on their various activities and projects, determining what purposes are more 
important than others and choosing not to take steps to accomplish one purpose if that will prevent them from achieving a more important purpose. Finally, persons are beings who place value on things according to how they judge each thing's contribution to their overall well-being and happiness. (33-34)

[Persons must have] a sense of their own identity over time. For they must be able to conceive of themselves as having a future, and this means that they believe that they will be the same persons later in life as the persons they are now, however different may be their external circumstances. To have a vision of one's life as a unified whole and to make judgements in the light of that vision requires a sense of personal identity. Only beings with that kind of self-awareness can be persons. (35)

Persons are agents, but not necessarily moral agents. Agents can follow nonmoral rules of "a voluntary association, ... a contest or game, ... how-to ... achieve a certain goal, ... society ... a state" (29), but need not adhere to moral values. Agents also must have self-consciousness through time, which is necessary to intentional action. To intend to do something one must know one intends to do it; only what an agent does intentionally counts as an action for the agent.

Taylor says only individual living organisms can be persons and agents (he modifies this condition later), because only individual organisms can be teleological centers of life in the sense that "the organism as a whole is the unit that responds to its environment and so accomplishes (or tends to accomplish) the end of sustaining its life" (122). Being a person thus depends on being a teleological center of life, but Taylor says a teleological center of life need not be a person:

Understanding individual organisms as teleological centers of life does not mean that we are falsely anthropomorphizing. It does not involve "reading into" them human characteristics. We need not, for example, consider them to have consciousness. That a particular tree is a teleological center of life does not entail that it is intentionally aiming at preserving its existence, that it is exerting efforts to avoid death, or that it even cares whether it lives or dies .... organisms like trees and onecelled protozoa do not have a conscious life. They are not aware of the world around them. They have no thoughts or feelings and hence no interest in anything that happens to them. Yet they have a good of their own around which their behavior is organized. All organisms, whether conscious or not, are teleological centers of life in the sense that each is a unified, coherently ordered system of goal-oriented activity that has a constant tendency to protect and maintain the organism's existence.

Under this conception of individual living things, each is seen to have a single, unique point of view. This point of view is determined by the organism's particular way of responding to its environment, interacting with other individual organisms, and undergoing the regular, lawlike transformations of the various stages of its species-specific life cycle. (121-122)

I now argue that it does not make sense to talk of a non-self-conscious entity's being a teleological center having a-good-of-its-own. If having inherent worth leading to moral subjecthood depends on an entity's being a teleological center that has a-good-of-its-own, then only selfconscious persons can be moral subjects. This conclusion is independent of whether or not those persons are humans. Thus on Taylor's own terms, my argument is not anthropocentric. Taylor's environmental ethics fails because he tries to prove that all living organisms are primary moral subjects with an unsuccessful argument that all and only living organisms are teleological centers of life.

Contrary to Taylor, it is not "meaningful to speak about what is good or bad for [any living] organism as seen from the standpoint of its own good" (67). It is impossible to "take the standpoint" of any non-self-conscious organism to determine "its own" good because a non-self-conscious entity cannot be a teleological center and thus cannot have "a-good-of-its-own." 
Taylor always speaks as though we learn of the objective conditions of an entity's survival or preservation by subjectively taking that entity's standpoint or point of view. But we in fact learn what conditions facilitate or impede its survival by objective observation of its behavior, for which we do not have to pretend to be its consciousness. Logically, we cannot pretend to be its consciousness because the entities in question are not self-conscious, and thus have no minds or mental standpoint to take. But this does not vitiate our ability to understand such an entity's objective interests in the sense of our knowing "the environmental conditions it needs to survive in a healthy state ... what is beneficial to it and what might be harmful to it" (66).

Taylor goes from the fact that non-self-conscious entities have objective interests to the conclusion that we can take their subjective standpoint to determine their subjective interests (67) so they are moral subjects. Thus he goes from "is" to "ought" although he denies that it can be done (51). That is, he infers from the fact that there are objective conditions that will harm or benefit an entity that it has moral status (inherent worth).

Note that I am arguing explicitly that we cannot imagine taking an imagined standpoint or point of view of an entity that does not actually have one without entering the fantasy world of children's stories. Taylor claims that he does not base his environmental ethics on anthropomorphizing sentimentality, but his use of "moral subject" to refer to non-self-conscious entities leads him to talk as though non-self-conscious entities have subjective standpoints or points of view which we can take. This is anthropomorphizing.

Taylor says explicitly about inanimate objects what $I$ argue is also true of non-self-conscious, non-agent, non-person living organisms. If we keep a sandpile dry, "it is not the sand's own good that would be furthered, but [our] purpose for which it is to be used... The sand has no good of its own. It is not the sort of thing that can be included in the range of application of the concept entity-that-has-a-good-of-its-own" (6061). Likewise, Taylor says that "purpose is not attributable to [a] machine. ... It is not the machine's own good that is being furthered by being kept well-oiled, but the good of certain humans for whom the machine is a means to their ends" (61):

This mode of understanding a particular individual is not possible with regard to inanimate objects. Although no two stones are exactly alike in their physical characteristics, stones do not have points of view. In pure fantasy, of course, we can play at performing the imaginative act of taking a stone's standpoint and looking at the world from its perspective. But we are then moving away from reality, not getting closer to it. The true reality of a stone's existence includes no point of view. This is not due to the fact that it lacks consciousness. As we have noted, plants and simple animal organisms also lack consciousness, but have points of view nonetheless. What makes our awareness of an individual stone fundamentally different from our awareness of a plant or animal is that the stone is not a teleological center of life, while the plant or animal is. The stone has no good of its own. We cannot benefit it by furthering its wellbeing or harm it by acting contrary to its well-being, since the concept of well-being simply does not apply to it.

This point holds even for those complex mechanisms (such as self-monitoring space satellites, chess-playing computers, and assembly-line "robots") that have been constructed by humans to function in a quasiautonomous, self-regulating manner in the process of accomplishing certain purposes. Though such machines are understandable as teleological systems, they remain in actual fact inanimate objects [Taylor later modifies his claim that only living organisms are teleological systems as contrasted to animate objects that are merely "understandable as" such]. The ends they are programmed to accomplish are not purposes of their own....

The goal-oriented operations of machines are not inherent to them as the goal-oriented behavior of organisms is inherent to them. (123-124) 
Note that machines are said not to have purposes of "their own" but to accomplish purposes of their human makers. Such purposeless machines are contrasted to non-self-conscious living organisms that are said to have purposes of their own, but these purposes cannot be like the intentional purposes of the human beings that program machines, because non-self-conscious organisms do not have minds. I argue that entities that cannot self-consciously intend their own purposes are not and cannot be (as contrasted to "being understood as") teleological systems ${ }^{1}$. What Taylor says next of machines is also true of non-self-conscious organisms:

[T] he goals of machines are derivative, whereas the goals of a living thing are original. The ends and purposes of machines are built into them by their human creators... Although they manifest goal-directed activities, the machines do not, as independent entities, have a good of their own. Their "good" is "furthered" only insofar as they are treated in such a way as to be an effective means to human ends.

A living plant or animal, on the other hand, has a good of its own in the same sense that a human being has a good of its own. It is, independently of anything else in the universe, itself a center of goal-oriented activity [Whose goals? Its own, if it is selfconscious; perhaps no one's if it is not]. What is good or bad for it can be understood by reference to its own survival, health, and well-being [its own?]. As a living thing it seeks its own ends in a way that is not true of any teleologically structured mechanism. It is in terms of its goals [Taylor's emphasis] that we can give teleological explanations of why it does what it does. [But the question just is whether or not an entity that does not have a mind, sense of self, and conscious intentions can have its own "why" or seek its own goals in the sense required to designate it as a teleological system.] We cannot do the same for machines, since any such explanation must ultimately refer to the goals their human producers had in mind when they made the machines. (124)
Now follows a key paragraph showing that Taylor sees that the distinction between teleological and non-teleological entities is neither based upon nor coextensive with (as he says it is) the distinction between living organisms and inanimate matter, but on the distinction between entities that are self-conscious and those that are not:

I should add as a parenthetical note that this difference between mechanism and organism may no longer be maintainable with regard to those complex electronic devices now being developed under the name of artificial intelligence. Perhaps some day computer scientists and engineers will construct beings whose internal processes and electrical responses to their surroundings closely parallel the functions of the human brain and nervous system. Concerning such beings we may begin to speak of their having a good of their own independently of the purposes of their creators. At that point the distinction drawn above between living things and inanimate machines may break down. (124-125)

The breakdown would come because, as Taylor implies here, such machines would be self-conscious, as humans are. They would have minds, so they could have intentions, purposes, and goals of their own. They would then be teleological centers, as non-self-conscious entities are not. Taylor ignores this insight. He goes on to claim that:

Our ability to understand and take the standpoint of individual organisms depends ... on our conceiving of them as teleological centers of life. Our disposition to conceive of them this way is supported by our looking at ourselves and them as fellow members of a community of life that includes both of us on equal terms. To the extent that we see ourselves to be one with other living things in the Earth's biosphere, to that extent we are able to achieve the frame of mind for having a full sense of the reality of their individual existences. (125) 
Being "fellow members of a community of life" is based only on being a living organism, which is not enough to establish that an entity has an individual existence as a teleological center. Taylor goes on:

We achieve wholeness of vision in our understanding of an animal or plant to the extent that we no longer look at it in terms of a role or function it might have in human life....

To free ourselves from such one-sidedness is to gain an understanding of the whole character or "personality" [Note the qualification here; Taylor knows that only persons actually have personalities and wants here to avoid being accused of anthropomorphizing; he should use the same caution in potentially misleading uses of "standpoint or point of view"] of an individual based on our recognition of its concrete qualities in all their particularity .... in our grasp of an organism's uniqueness, we come to know the life of that individual as lived by it. [But every particular entity is unique, so our grasp of uniqueness does not establish that we "know the life of that individual as lived by it." Taylor says correctly on p. 122 that non-self-conscious entities cannot live their own lives, i.e., they do not have their own lives]....

When our consciousness of the life of an individual organism is characterized by both objectivity and wholeness of vision, we have reached the most complete realization, cognitively and imaginatively, of what it is to be that particular individual. We have let the reality of another's life enter into the world of our consciousness. We know it as fully and intensely as it can be known....

As a result of our heightened awareness of the reality of another living thing's existence, we gain the genuine capacity to take its standpoint and make judgments based on its good. Shifting out of the usual boundaries of anthropocentricity, the worldhorizon of our moral imagination opens up [metaphorically and anthropomorphically] to encompass all living things. Seeing them as we see ourselves, we are ready to place the same value on their existence as we do on our own. (128)

I have two arguments here. First, in his discussion of stones and machines, Taylor shows that we can learn by objective observation about the conditions that will disrupt or facilitate the survival or preservation of non-self-conscious entities. Taking the imagined subjective standpoint of such an entity is not necessary for learning about these conditions. In fact, the only sense of "standpoint or point of view" that Taylor actually presents for non-self-conscious entities makes the phrase merely a way of referring to objective conditions. His use of "standpoint or point of view" with its subjective nuances confuses the reference to these objective conditions and is an unwarranted verbal bridge to the false conception that non-self-conscious entities can have, do have, or can be imagined to have subjective points of view.

Second, Taylor's discussion of the fact that non-self-conscious entities cannot have knowledge of themselves because they cannot have knowledge of anything is equivalent to saying that they do not have selves. We cannot "see them as we see ourselves" because we cannot imaginatively take the standpoint of an entity that does not and cannot have self-conscious experiences, i.e., cannot see themselves. It is thus just as much fantasy to project oneself imaginatively into the "life" of a non-self-conscious organism as it is to pretend to be a stone or a machine.

Explicitly, there is no "what it is to be" a nonself-conscious entity. It is sheer nonsense to talk of any non-self-conscious entity as though we could "achieve a full understanding of the point of view defined by its good" (129). For something to have "a-good-of-its-own" and a "what it is to be" that entity, it must be conscious of its own good and its own being. By definition, non-selfconscious beings do not own or have "their own lives."

Beyond that, if it is a category mistake to make merit comparisons between entities that do and do not have self-consciousness ( $130 \mathrm{ff}$ ), then it is also wrong (as I have detailed,) to say that a self- 
conscious entity can "take the standpoint" of a non-self-conscious entity (that does not have a standpoint in the self-conscious sense that is purportedly taken for it).

What we do when we "take the standpoint or point of view" of a non-self-conscious living organism, or, for that matter, a mountain, is fancifully pretend what it would be like to be selfconscious in that kind of organism or thing. In charades, one tries to posture one's body so it looks like a mountain. When stalking rabbits to photograph them in the wild, one reviews what one knows about rabbit behavior. It would be a mistake to think what one might do next if one had the body of a rabbit and were being stalked, because rabbits do not behave when stalked as you would if you had the body of a rabbit. Wild rabbits are easy to stalk because their speciesspecific behavior is very predictable, something we learn by observing them objectively, not by subjectively "taking their standpoint." One's success in charades or in photographing wild rabbits is not, then, because we plug into "what it is to be" a mountain or into "the reality of a rabbit's life," because non-self-conscious entities do not have ways of being nor anything that is their way of life.

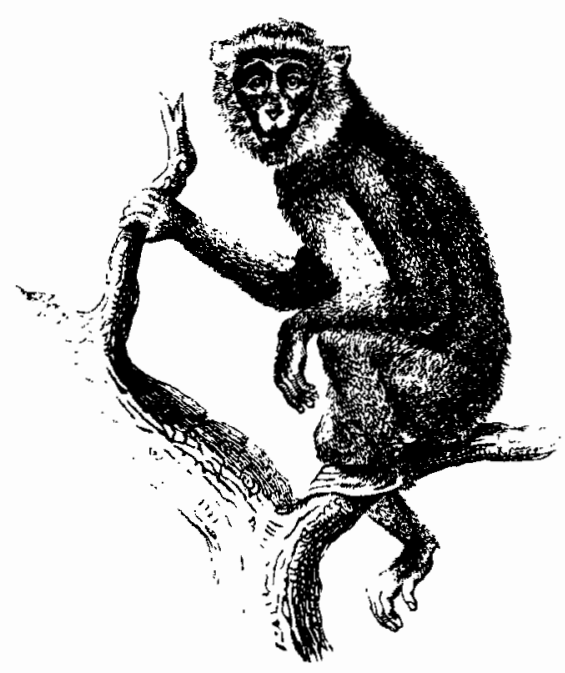

The necessary condition for having a standpoint or point of view is not that of being a living organism (or that of being a teleological center of life in Taylor's sense, which I argue is too broad), but that of having consciousness of one's self as occupying the standpoint from which one has a point of view. So we cannot "take the standpoint" of a non-self-conscious entity. But we can take the standpoint or point of view of other selfconscious entities.

Similarly, non-self-conscious entities do not have their own goals. Not all living organisms have goals, so they cannot be separated from machines or inanimate things on the basis that all living organisms are teleological centers. Only some are and can be so separated. Taylor says that machines cannot have standpoints and goods-of-their-own because machines are artifacts that facilitate their makers' goals. People who believe that God made all nonhuman living organisms for human use say the same thing about them. Biologists say living organisms behave the way they do not on purpose but because they have been conditioned by processes of natural selection. Most living organisms do not have their own goals but like some machines merely look as though they do to self-conscious entities who are aware of themselves as having goals. It is precisely to avoid the anthropomorphic fallacy that behaviorist psychologists and biologists methodically do not "take the organism's standpoint." To speak of a non-selfconscious entity's having a standpoint or point of view and a-good-of-its-own is anthropomorphic because it is to pretend that it is self-conscious as humans are. This impossibility is just what Taylor's position requires of us.

To be very clear about this, let me say that I think that many nonhuman animals - at least dolphins, whales, elephants, and the great apes - are self-conscious through time and so do have standpoints or points of view that we can imaginatively project ourselves into. This makes them persons. But note that if inherent worth, in Taylor's sense as worthy of respect, applies only to entities whose standpoint we can take, the concept is far from covering all living organisms. And given that a person is not necessarily an agent, and an agent is not necessarily a moral 
agent, if moral categories apply only to moral agents (as reciprocity theorists of ethics argue), then we are also far from having reason to say that all persons or all agents are worthy of respect. Taylor treats reciprocity theory - that moral categories apply only to agents who can have both rights and duties - as being special to human ethics, but obviously it can be extended to any domain of agents, whether they are human or not.

It makes sense imaginatively to take the standpoint or point of view of another self-conscious person. As Taylor says:

If one does not have the capacity for imaginative awareness of another person's experienced world, one will not be able fully to conceive of what it means to be that other person living his or her life. On the other hand, to the extent that we develop the imaginative power to envisage what it is like to experience the world as other people do, to that extent we are able to achieve in our own consciousness a clear grasp of the reality of others' lives. Our sense of another person's existence then becomes a recognition that the other is a subjective center of awareness, just like ourselves. (128)

What is essential here is the other's possession of "a subjective center of awareness," which I argue an entity must have if it is to be a teleological center. Thus I deny that:

Our conceiving of each organism as a teleological center of life is our recognition of the reality of its existence as a unique individual, pursuing its own good in its own way. By developing the powers of heightened awareness of it as the particular individual it is, we achieve a full understanding of the point of view defined by its good. (129)

Taylor himself provides the argument for the inconceivability of this kind of empathetic understanding of non-self-conscious entities. What he says about bearers of moral rights, I say with respect to bearers of inherent worth as Taylor defines it:
If it is to make sense to say that bearers of moral rights are entitled to press their rights against moral agents and to demand that all such agents respect their rights, it must be theoretically possible for them to do what they are entitled to do. That is, it must be conceivable for them to press their claims against others if they choose to.... It is a matter of logical conceivability. What it means to press claims against others and demand that the legitimacy of those claims be acknowledged is simply incompatible with what it means to be an animal or a plant. An animal or plant would not be the kind of thing it is if it were possible for us to conceive of it as choosing to press its legitimate claims against moral agents and to demand that they acknowledge the legitimacy of its claims. Therefore ... it is inconceivable for animals and plants to be bearers of moral rights. (247)

I explicitly deny that it is theoretically conceivable for a non-self-conscious entity to be a teleological center and thus have inherent worth.

Taylor says that "As moral agents we see ourselves under an ethical requirement to give equal consideration to the good of every entity, human and non-human alike, that has a good of its own" (158). One can agree with this and still have an ethics that is neither biocentric nor anthropocentric. Its scope would cover all self-conscious persons, but not necessarily all agents and not necessarily all humans. Taylor seems to support this scope of moral respect in stating the principle that "Moral agents are permitted to defend themselves against harmful or dangerous organisms that are not moral agents" (266-267). He stresses that "The statement of the principle refers only to moral agents and organisms (of whatever species) that are not moral agents" so it is not anthropocentric (266). But it is agent-centered. At most, Taylor's notions of taking an entity's standpoint and of an entity's own good allow extension of moral scope only to entities that are self-conscious persons (who might not be agents). I see nothing wrong with this, agreeing totally with Taylor's exposition of the fact that we can assign legal rights to non-persons for their protection or preservation. 
In sum, one obviously can and does gain objective (not subjective) knowledge "of the individuality of each living thing ... through close observation of its behavior and environmental circumstances" (165). But it is misleading and unnecessary nonsense to say that this knowledge is "a state of heightened consciousness" from which

one becomes more fully and more deeply cognizant of what it means to be that particular center of life. One is thus enabled to take its standpoint and imaginatively to view the world from its perspective. On the basis of this capacity one can then make accurate judgments concerning what is favorable or detrimental to the realization of its good. (165)

Nevertheless, such "standpoint" talk is harmless as long as one realizes that all that is being said is that we can learn objectively about the life cycles of different species of organisms and the behavior of particular individuals by observing them, and on the basis of that knowledge can do things that will facilitate or hinder their survival. But Taylor uses such metaphorical talk in an attempt to convince others that all living non-self-conscious entities are teleological centers with goods of their own. He uses this false claim to bolster his recommendation of a life-centered environmental ethics in which all living organisms are worthy of equal respect. And that view, as I have shown, he cannot support.

There is a considerable amount in Taylor's book that I do agree with: his laudable concern for individuals; most of what he says about human rights and particularly about stipulating legal rights to non-conscious entities $(222,253-$ 254), and in the second half of his book, much of the substantive working out of moral conflicts when one assumes that entities other than humans have inherent worth or moral rights.

But Taylor fails in his attempt to avoid arguments against animals having moral rights by using the phrase "inherent worth" to refer to the content of "moral rights" (254-255), for he says explicitly that they mean the same thing, that "The use of the language of rights introduces no new concepts" (254). He must see that if the concept of an animal's having a moral right can be criticized as he has done, then the same concept referred to with the phrase "inherent worth" can be so criticized also. Taylor thus himself shows how to argue against the view that non-self-conscious entities have inherent worth. I add the related argument that because his crucial concept of inherent worth - like that of having a moral right - depends on taking a standpoint, it incorporates the illegitimate importation of imaginary personhood by the pretense that non-self-conscious animals and plants have subjective standpoints with which we can empathize and from which we can speak for them by recognizing their own goods.

Let me close by remarking that Taylor, like many environmental ethicists, appears to be (I know he is not) ignorant of the strength of the opposition. He presents a biocentric environmental ethics on the unargued assumption of materialist scientific realism, "the entire outlook is firmly rooted in the findings of the physical and biological sciences" (160). His brief argument against Biblical ethics (139-143) is to show that it is anthropocentric! He does not even begin to face the problem that belief in revelation from some God is the basis of most systems of ethics accepted by most humans in the world today. How easy if religious belief in theological ethics could just be put aside! Taylor himself makes implicit appeal to religious sentiments by capitalizing the phrase "Community of Life" (99, passim) and by using the religious rhetoric of commitment and conversion $(98,134,154-157$, 312 ). And his explanation that moral validity (see index) depends on belief in the very principles being validated sounds very like pleas that belief in Jesus (or in Peter Pan and the fairies?) will make it true.

Taylor does not even consider idealism. If he took idealism at all seriously, he could not pander as he does to death-wish misanthropy by saying that "It is not inconsistent for a human to believe in all sincerity that the world would be a better place if there were no humans in it" (52) and that "if we were to take the standpoint of that Life Community and give voice to its true interest, the ending of the human epoch on 
Earth would most likely be greeted with a hearty 'Good riddance!'” (115). This shows that metaphorical talk of taking non-self-conscious entities' standpoints is, after all, dangerous nonsense. The "Life Community" has no standpoint, and Taylor's own text shows that so far as we know concerning earth's inhabitants, if there were no humans on earth, there would be no one who could say (or think) "Good riddance!" So why does he perpetrate this cant that on the one hand supports the ideology of the "rights" of the state or of the "corporate person" against individuals and on the other hand expresses genocidal hatred for the human race!

Both from many religious viewpoints and from the idealistic viewpoint, it is strictly inconsistent to say that the world would be a better place without humans, because if there were no humans in it, for Christians, for example, the world would have no value at all, and for idealists the world would not exist. I am not convinced that either of these views makes sense, but I do not think they can just be dismissed. Moreover we should not forget that Aristotelians find teleological forces and goods in all things. Taylor is not an Aristotelian because he denies that inanimate entities are teleological centers.

Taylor asks that biocentric environmental ethics be considered on the basis of his complete presentation of it. What his presentation shows is the strength of the claim that the institution of morality is generated through interactions among person-agents who have mutually agreed to abide by a set of rules that designates reciprocal rights and duties among themselves. In such a system, nothing is primarily morally good or bad, right or wrong, except moral agents and their actions, and - by metaphorical allusion - the results and objects of their actions. Taylor agrees with this reciprocity theory of ethics for humans and other agents, but he wants all living organisms to be primary moral subjects. Taylor both fails to establish this and shows that it is not necessary. Anything (all "subjects") that agents want to protect other than themselves can be given secondary stipulative rights - call them legal or moral, it does not matter which, so long as they are respected.
By all means let us have respect for nature. But as agents and as philosophers, let us be clear about exactly what this means. An agent- or person-oriented ethics, as Taylor points out, is not strictly speaking anthropocentric even if the only moral agents we know of are humans. Despite Taylor's talk of the standpoints or points of view, goods of their own, and inherent worth of all living organisms, he shows at most that these concepts apply only to person-agents. In his attempt to make all living organisms into moral subjects he obscures the useful non-anthropocentric distinction between primary and secondary moral subjects. It makes no sense to talk of a quasi-religious Community of Life consisting of all living organisms that are primary moral subjects because they are teleological centers that have goods-of-their-own that give them inherent worth, which means that we should respect them. On the other hand, it does make sense to say that living organisms - and, as far as that goes, mountains, which Taylor denies moral subjecthood because he knows we cannot think like a mountain - be given stipulative, secondary moral status by moral agents. Taylor does not, and with his naturalistic foundation (160), cannot, show that more than this is possible. Why isn't it enough?

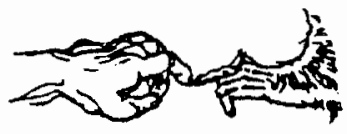

\section{$\underline{\text { Note }}$}

${ }^{1}$ See my arguments for the priority of self-consciousness in the following articles: "SelfConsciousness and the Rights of Nonhuman Animals and Nature," Environmental Ethics, Vol. 1, 1979, pp. 99-129; "Self-Conscious Rights," Ethics and Animals, Vol. 2, 1981, pp. 90-92; "Interests, Rights, and Self-Consciousness," Environmental Ethics, Vol. 4, 1982, pp. 285-287. On taking points of view, see Thomas Nagel, "What Is It Like To Be A Bat?" Philosophical Review, Vol. 83, 1974, pp. 435-450. 